\title{
アミノ酸の界酒活性ミ゙吸趄ミに就て（第四垠）
}

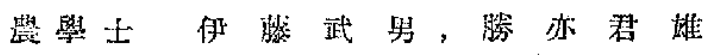

(昭和七年三月二十日受理)

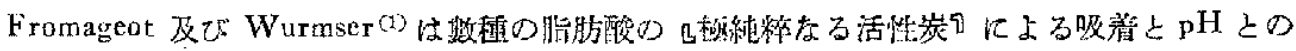

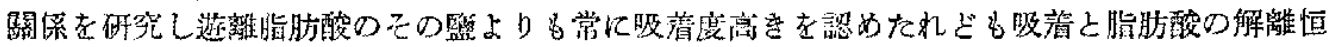

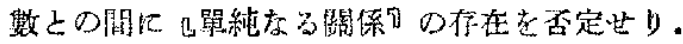

Phelps 及び Peters(2) Miller(3)の方法にて精製せる Norit（炏分 $0.07 \%$ 以下）に上る

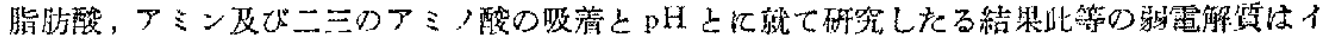
オン化せざる分子として财蔳せらると維詇ぜり。

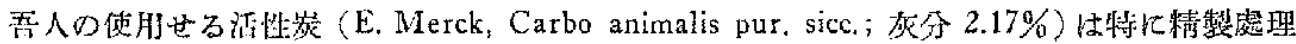

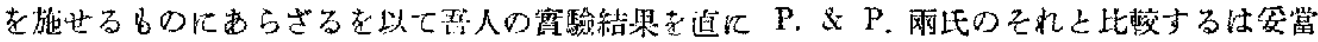

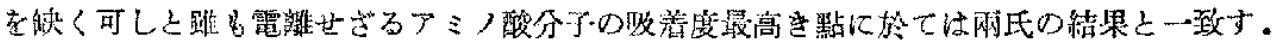

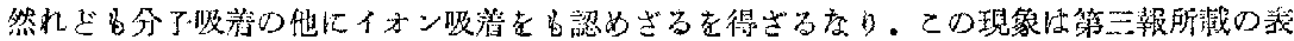

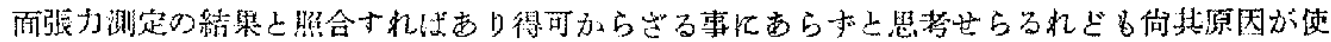

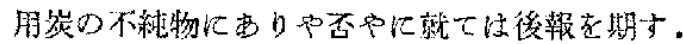

\section{菑 驗}

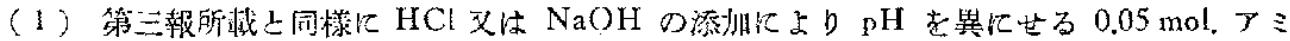

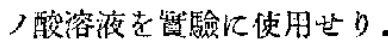

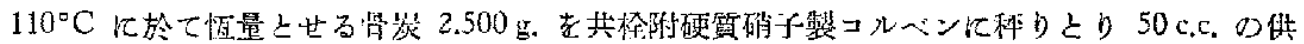

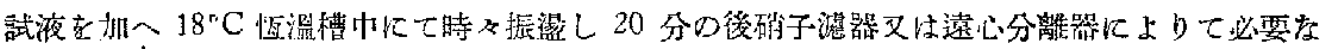

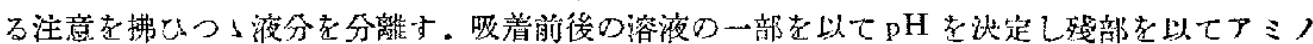

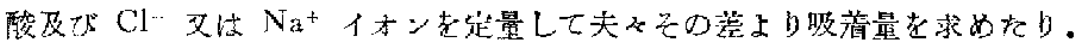

アミノ酸はvan Slyke法により，Cl-イオンはV Volhard法により又 $\mathrm{Na}^{\circ}$ イオンは $\mathrm{Na}_{2} \mathrm{SO}_{4}$ として定量せり.

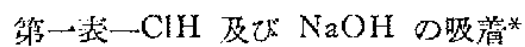

\begin{tabular}{|c|c|c|c|c|}
\hline \multirow{2}{*}{ 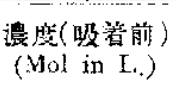 } & \multicolumn{2}{|c|}{$\mathrm{CH}$} & \multicolumn{2}{|c|}{$\mathrm{NatiHI}$} \\
\hline & PII (昅着後) & 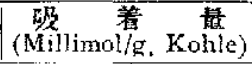 & $\mathrm{pHI}$ (吸着後) & (Millimol/g. Kohle) \\
\hline 0.00625 & $\overline{218}$ & $\overline{0.088}$ & 10.90 & 0.095 \\
\hline $\begin{array}{l}0.0125 \\
0.025\end{array}$ & $\begin{array}{l}2.18 \\
1.81\end{array}$ & 0.099 & $\begin{array}{l}11.87 \\
12.31\end{array}$ & $\begin{array}{l}0.128 \\
0.152\end{array}$ \\
\hline 0.0375 & 1.59 & 0.129 & & \\
\hline 0.05 & 1.47 & 0.144 & 12.69 & 0.178 \\
\hline 0.075 & 1.27 & 0.174 & 7309 & 0101 \\
\hline $\begin{array}{l}0.1 \\
0.15\end{array}$ & $\begin{array}{l}1.14 \\
0.96\end{array}$ & 0.184 & 13.02 & 0191 \\
\hline 0.2 & 0.83 & 0.234 & 13.25 & 0.207 \\
\hline
\end{tabular}

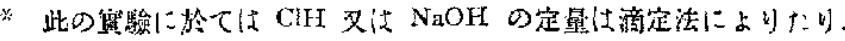




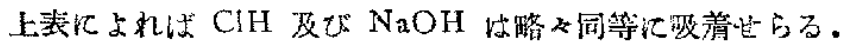

第二表一Glykokoll

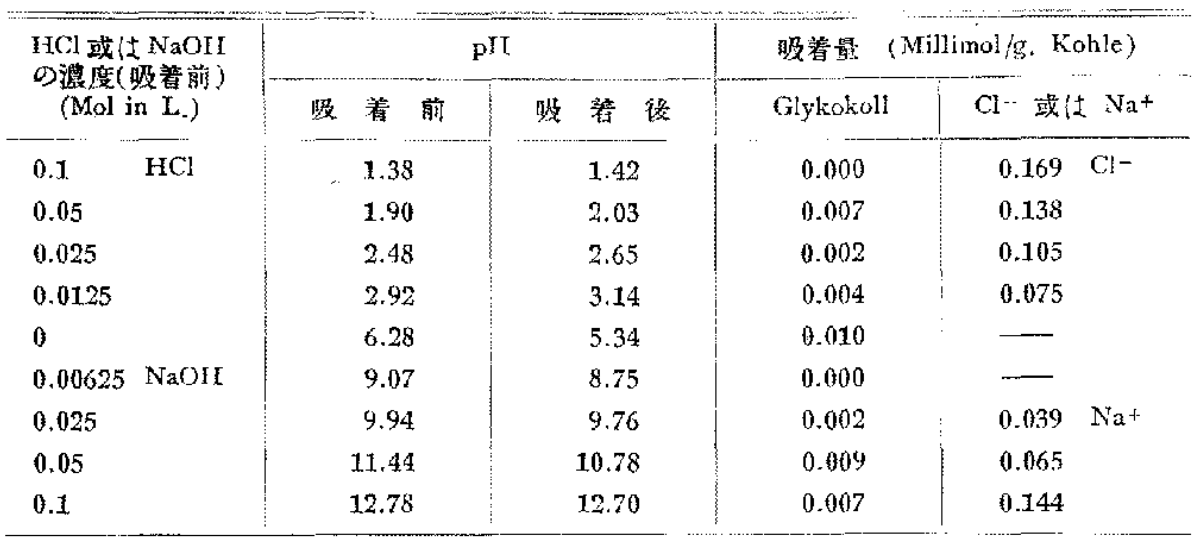

第三表--Alanin

\begin{tabular}{|c|c|c|c|c|c|c|c|}
\hline \multirow{2}{*}{\multicolumn{2}{|c|}{$\begin{array}{c}\mathrm{HCl} \text { 㖪( } \mathrm{NaOH} \\
\sigma \text { 遭度( 吸者後) } \\
\text { (Mol in I.) }\end{array}$}} & \multicolumn{4}{|c|}{$\mathrm{pH}^{\mathrm{H}}$} & \multicolumn{2}{|c|}{ 吸着量 (Millimol /g. Kohle) } \\
\hline & & \multirow{2}{*}{\multicolumn{2}{|c|}{$\begin{array}{c}\text { 的着 前 } \\
1.11\end{array}$}} & \multirow{2}{*}{\multicolumn{2}{|c|}{ 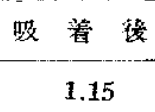 }} & \multirow{2}{*}{ Alavin } & $\mathrm{Cl}-$ 或蛅 $\mathrm{Cl}+$ \\
\hline 0.15 & $\mathrm{HCl}$ & & & & & & $0.258 \quad \mathrm{Cl}^{-}$ \\
\hline 0.1 & & & 1.37 & & 1.43 & 0.033 & 0.224 \\
\hline 0.05 & . & & 1.95 & & 2.08 & 0.038 & 0.141 \\
\hline 0.0125 & & & 2,93 & & 3.10 & 0.029 & 0.074 \\
\hline 0 & & & 6.73 & & 5.35 & 0.028 & - \\
\hline 0.00625 & $\mathrm{NaOI}$ & & 9.21 & & 8.86 & 0.030 & - \\
\hline 0.025 & & & 10.02 & & 9.83 & 0.027 & $0.038 \mathrm{Na}+$ \\
\hline 0.05 & & & 11.36 & & 10.79 & 0.034 & 0.070 \\
\hline 0.1 & & & 12.78 & & 12.38 & 0.0 .34 & 0.136 \\
\hline
\end{tabular}

\begin{tabular}{|c|c|c|c|c|c|c|c|c|}
\hline \multirow{2}{*}{\multicolumn{2}{|c|}{$\begin{array}{c}\mathrm{HCl} \text { 成( } \mathrm{NaOH} \\
\text { D濃度(吸者前) } \\
\text { (Mol in L.) }\end{array}$}} & \multicolumn{4}{|c|}{ pH } & \multicolumn{3}{|c|}{ 砐着最 (Milimol/g. Kohle) } \\
\hline & & & 着 前 & 吸 & 蓄 徣 & Valin & $\mathrm{Cl}-$ 或は & $\mathrm{Na}+$ \\
\hline 0.15 & $\mathrm{HICl}$ & & 1.08 & & 1.09 & $(1.209$ & 0.396 & $\mathrm{C}:-$ \\
\hline 0.1 & & & 1.34 & & 1.40 & 0.205 & 0.354 & \\
\hline 0.05 & & & 1.91 & & 2.02 & 0.230 & 0.250 & \\
\hline 0.025 & & & 2.44 & & 2.56 & 0.240 & 0.151 & \\
\hline 0.0125 & & & 2.82 & & 3.00 & 0.232 & 0.089 & \\
\hline 0 & & & 6.36 & & 5.43 & 0.237 & - & \\
\hline 0.0125 & $\mathrm{NaOH}$ & & 9.38 & & 9.23 & 0.225 & $0.045 \quad 1$ & $\mathrm{Na}^{+}$ \\
\hline 0.025 & & & 9.84 & & 9.78 & 0.211 & 0.058 & \\
\hline 0.04 & & & 10.41 & & 10.30 & 0.176 & 0.100 & \\
\hline 0.05 & & & 11.23 & & 10.68 & 0.138 & 0.125 & \\
\hline 0.06 & & & 12.14 & & 11.64 & 0.103 & 0.154 & \\
\hline 0.075 & & & 12.49 & & 12,32 & 0.090 & 0.203 & \\
\hline 0.1 & & & 12.82 & & 12.72 & 0.083 & 0.243 & \\
\hline 0.15 & & & 13.06 & & 12.97 & 0.093 & 0.255 & \\
\hline
\end{tabular}


第五表一Leucin

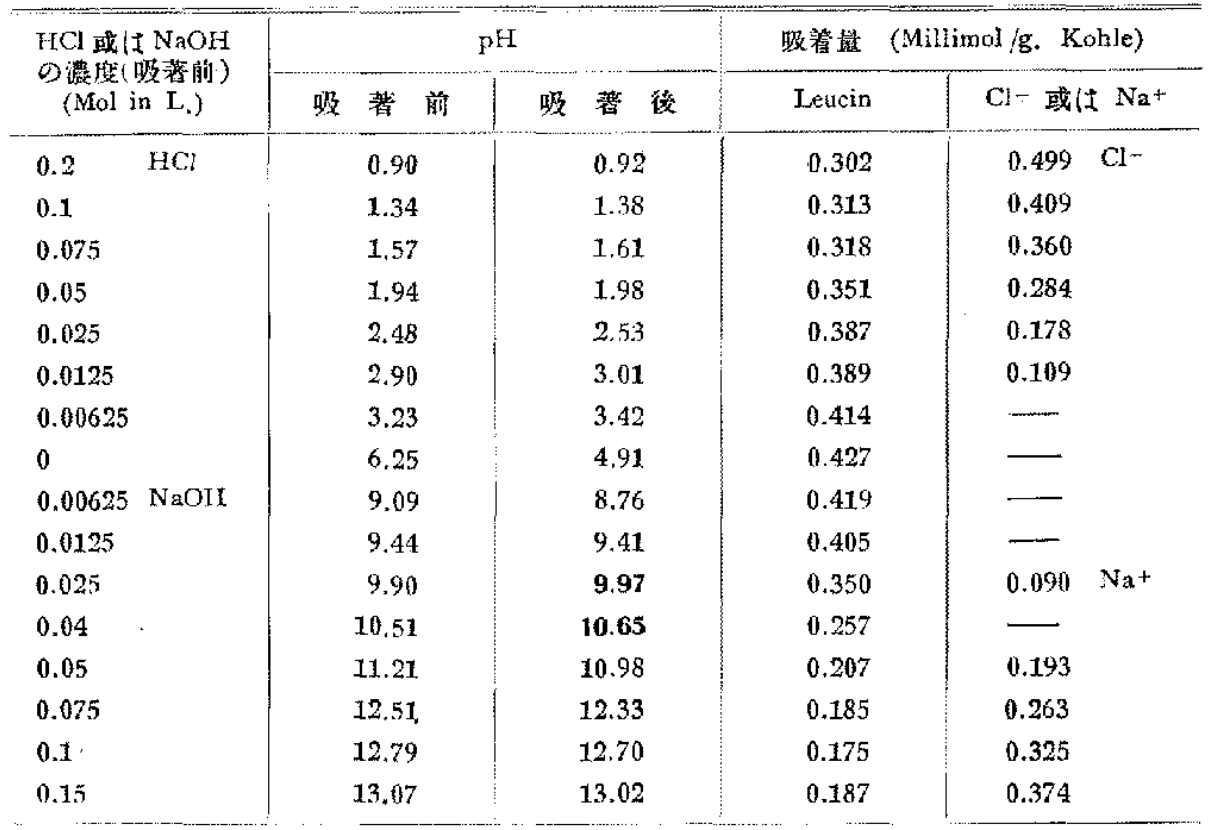

第六表-Norleucin

\begin{tabular}{|c|c|c|c|c|c|c|c|}
\hline \multirow{2}{*}{\multicolumn{2}{|c|}{ 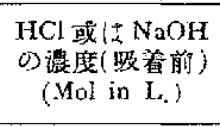 }} & \multicolumn{2}{|c|}{ pli } & \multirow{2}{*}{ 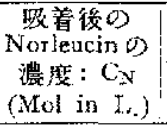 } & \multicolumn{3}{|c|}{ 昨着星 (Millimol/g. Kohle) } \\
\hline & & \multirow{2}{*}{$\frac{\text { 旳䉡 前 }}{1.13}$} & \multirow{2}{*}{$\frac{\text { 明着 娞 }}{\dot{1} 1.15}$} & & \multirow{2}{*}{$\frac{\text { Norleucin }}{0.448}$} & \multicolumn{2}{|c|}{$\mathrm{Cl}-$ 牫任 $\mathrm{Na}+$} \\
\hline 0.15 & $\mathrm{HCI}$ & & & 0.0276 & & 0.547 & $\mathrm{Cl}^{-}$ \\
\hline 0.1 & & 1.36 & 1.39 & 0.0273 & 0.454 & 0.492 & \\
\hline 0.075 & & 1.49 & 1.50 & 0.0281 & 0.438 & 0.424 & \\
\hline 0.05 & & 1.93 & 1.94 & 0.0250 & 0.499 & 0.354 & \\
\hline 0.025 & & 2.46 & 2.47 & 0.0228 & 0.543 & 0.225 & \\
\hline 0.0125 & & 2.91 & 2.97 & 0.0221 & 0.557 & 0.112 & \\
\hline 0.00625 & & 3.23 & 3.39 & 0.0214 & 0.571 & $\ldots$ & \\
\hline 0 & & 6.32 & 4.93 & 0,0213 & 0.574 & - & \\
\hline 0.00625 & $\mathrm{NaOH}$ & 9.1 .8 & 8.89 & 0.0213 & 0.573 & $\longrightarrow$ & \\
\hline 0.00125 & 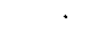 & 9.48 & 9.61 & 0.0234 & 0.531 & 0.062 & $\mathrm{Na}_{3}+$ \\
\hline 0.025 & & 9.99 & 10,21 & 0.0258 & 0.484 & 0.120 & \\
\hline 0.045 & & 10.93 & 11.13 & 0.0326 & 0.348 & 0.236 & \\
\hline 0.05 & & 11.31 & 11.23 & 0.0333 & 0.333 & 0.260 & \\
\hline 0.06 & & 12.16 & 11.94 & 0.0351 & 0.298 & 0.302 & \\
\hline 0.075 & & 12.54 & 12.38 & 0.0353 & 0.294 & 0.332 & \\
\hline 0.1 & & 12.79 & 12.71 & 0.0354 & 0.292 & 0.389 & \\
\hline 0.15 & & 13.06 & 13.04 & 0.0351 & 0.298 & 0.433 & \\
\hline
\end{tabular}

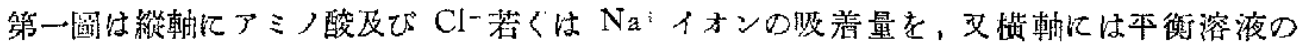

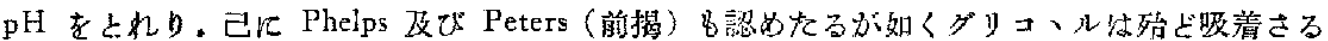




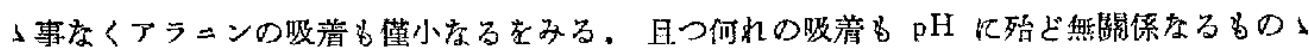

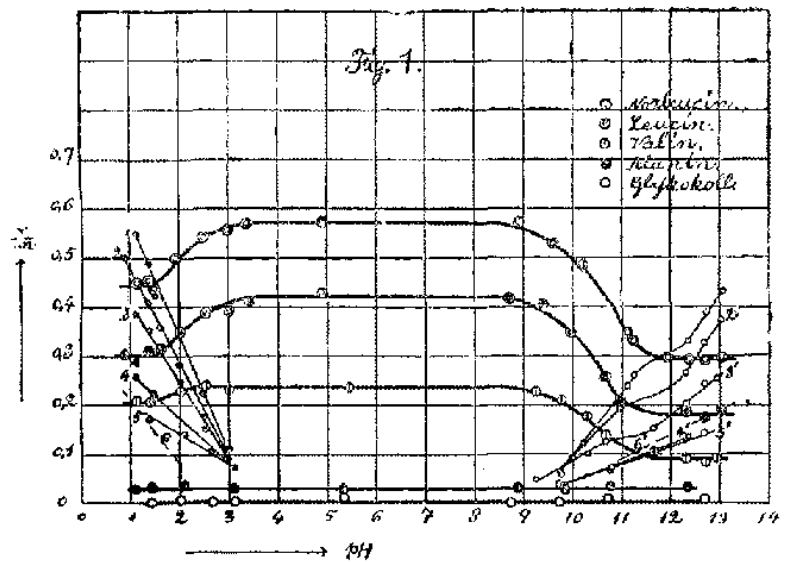

如 L.

ヴアリン，ロイシン及びノルロ

イシンは等電點（第三预案照）附

近の $\mathrm{pH}$ - 領域に於て接大吸着者

示せり.而して三者の吸着曲線は

相類似せる克以てノふロイシン老

代表として擇びその昅等相の組成

を检討せむに平衡豁液に於ける $\mathrm{pH}$ 上ノルロイシンの濃度 $C_{N}$

(第分表) とよりノルロイシン中

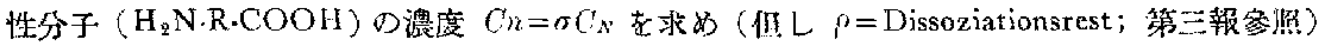
之娄

$$
\frac{x}{m}=2.27 C^{0.364}
$$

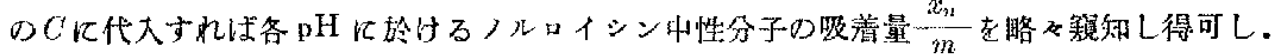

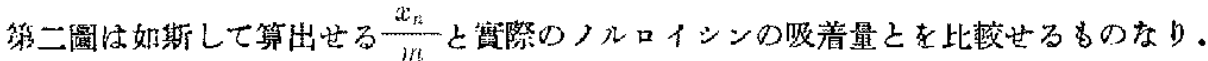

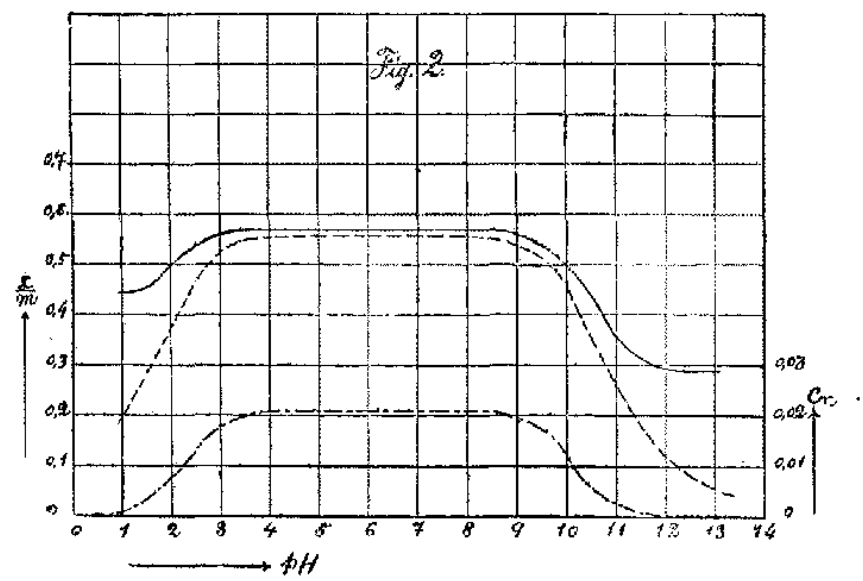

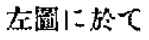

——ルロイシンの吸着曲線

$-\ldots-\frac{x_{72}}{m}-\mathrm{p} \mathrm{H}-$ 曲線

-.... $C n-\mathrm{pH}$ - - 曲線

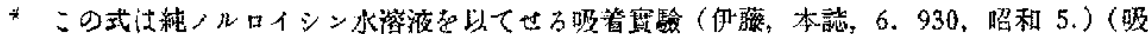

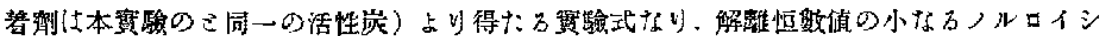

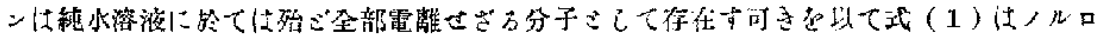

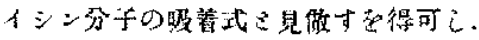

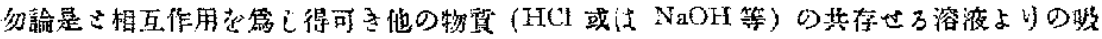

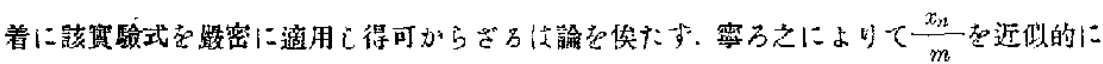
求め得ろに過ぎす。 


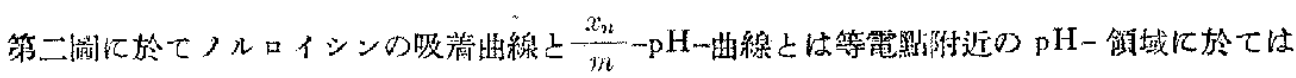

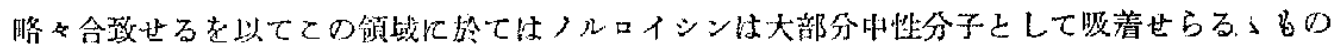

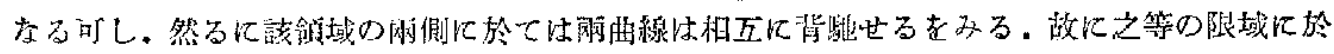

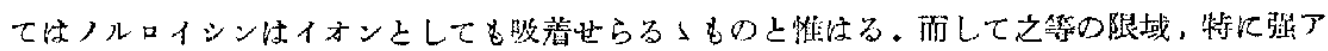

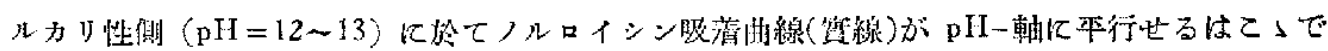
はそれが主としてイオンとして吸着世られ且つ乎衡容液中のノルロイシンイオンの濃度は $\mathrm{H}^{+}$

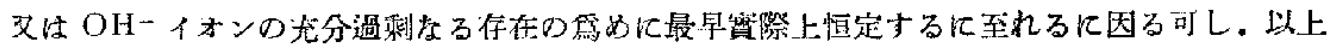

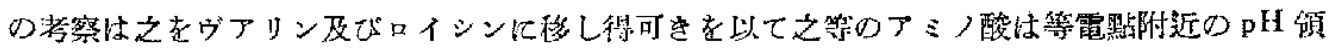
域に热ては大部介中性分了・として吸着せらるれども强酸性又性强了ルカリ性側に於ては主とし

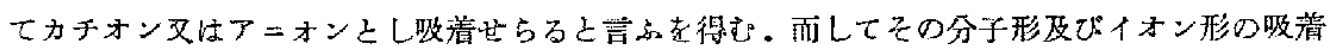
度の頼估林

$\mathrm{H}_{2} \mathrm{~N} \cdot \mathrm{R} \cdot \mathrm{COOH}$ (或は恐方く $\left.\mathrm{H}_{3}+\mathrm{N} \cdot \mathrm{R} \cdot \mathrm{COOH}^{-}\right)>\mathrm{H}_{3}+\mathrm{N} \cdot \mathrm{R} \cdot \mathrm{COOH}>\mathrm{H}_{2} \mathrm{~N} \cdot \mathrm{RCOO}-$

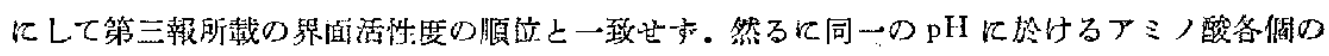
吸着庭支比较すれば常に

Norleucin > Leucin > Valin > Alanin > Glykokoll の順位にして界面活性度の順位 上一政士.

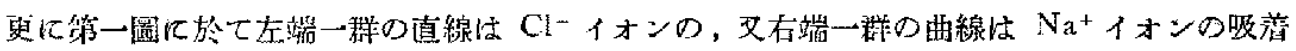
楾索り :-

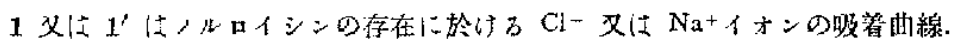

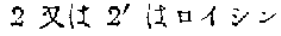

3㕛は3はがアリン

4 㕛江 $4^{\prime}$ 仗 $79:=$

5 又法5注ダリコ、ル

$"$ "

6 汒 $\mathrm{HCl}$ o吸着曲線（點線）

6' $12 \mathrm{NaOH} "$ (")

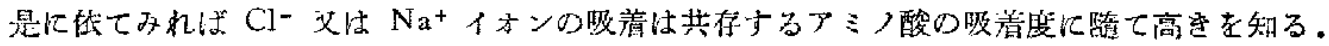

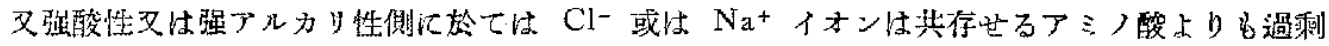
に吸着せらるな老みる。

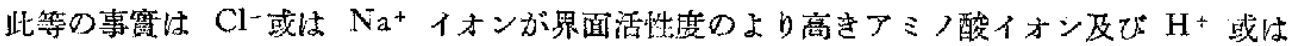

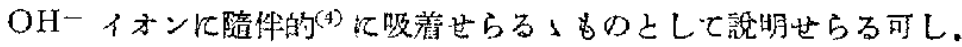

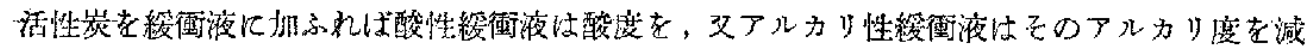

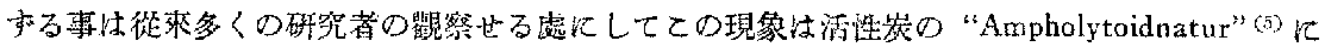
被せられたるもの小如し。

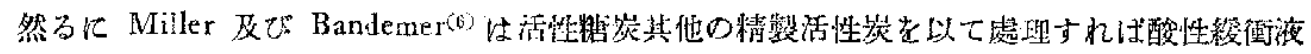

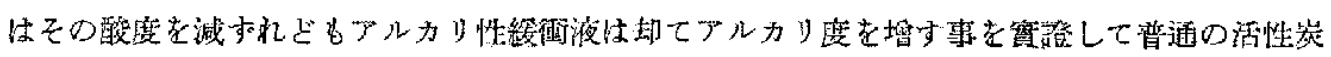

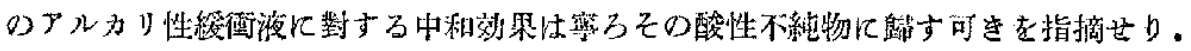




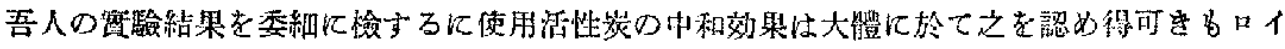

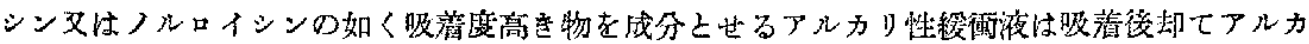

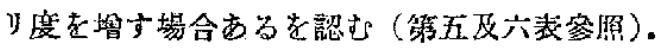

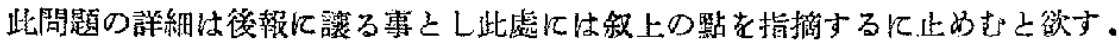

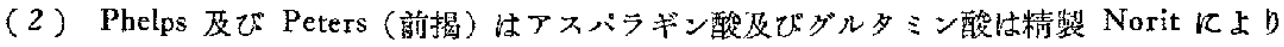

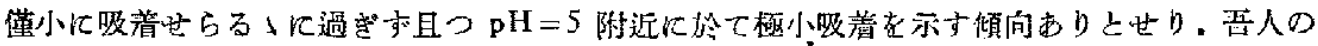

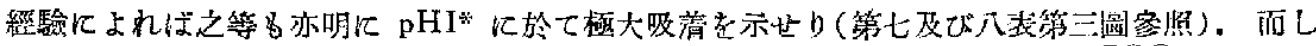
て之等のアミノ酸のカチネンは可成り昅着せらるれも゙もアニォンは $\mathrm{H}_{2} \mathrm{~N} \cdot \mathrm{R}\left\langle\mathrm{COOH}_{\mathrm{COO}}^{-}\right.$¿乙て

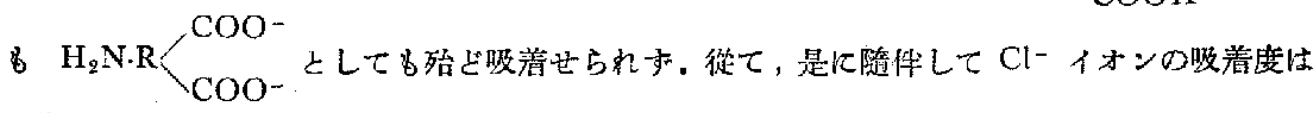

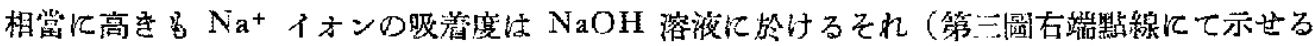
もの)上大差なし.

第比表-Asparaginsäure

\begin{tabular}{|c|c|c|c|c|c|c|c|c|}
\hline \multirow{2}{*}{\multicolumn{2}{|c|}{$\begin{array}{c}\mathrm{HCl} \text { 或( } \mathrm{NaOH} \\
\text { O濃度(吸着前) } \\
(\mathrm{Mol} \text { in L })\end{array}$}} & \multicolumn{4}{|c|}{$\mathrm{pH}$} & \multicolumn{3}{|c|}{ 报着舅（Millimol'g. Kohle) } \\
\hline & & 吸 & 都 前 & 吸 & 䈐 㻐 & Asparaginsäure & \multicolumn{2}{|c|}{$\mathrm{Cl}^{-}$或位 $\mathrm{Na}^{+}$} \\
\hline 0.1 & $\mathrm{IiCl}$ & & 1.32 & & 1.35 & 0.162 & 0.260 & $\mathrm{Cl}^{-}$ \\
\hline 0.05 & & & 1.79 & & 1.84 & 0.164 & 0.194 & \\
\hline 0.0125 & & . & 2.54 & & 2.63 & 0.224 & 0.071 & \\
\hline 0.00625 & & & 2.74 & & 2.81 & 0.233 & $\longrightarrow$ & \\
\hline 0.0031 & & & 2.01 & & 2.94 & 0.237 & - & \\
\hline$\theta$ & & & 3.16 & & 3.18 & 0.240 & $\longrightarrow$ & \\
\hline $0.00625 \mathrm{I}$ & $\mathrm{NaOH}$ & & 3.23 & & 3.30 & 0.228 & - & \\
\hline 0.0125 & & & 3.45 & & 3.58 & 0.210 & - & \\
\hline 0.025 & & & 3.86 & & 4.01 & 0.169 & -0.03 & $\mathrm{Na}^{+}$ \\
\hline 0.045 & & & 4.72 & & 5.01 & 0.078 & 0.00 & \\
\hline 0.05 & & & 6.64 & & 6.61 & 0.022 & 0.02 & \\
\hline 01 & & & 11.26 & & 10.67 & 0.000 & 0.079 & \\
\hline
\end{tabular}

第八表-Glutaminsäure

\begin{tabular}{|c|c|c|c|c|c|c|c|}
\hline \multirow{2}{*}{\multicolumn{2}{|c|}{ 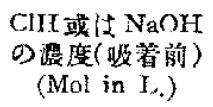 }} & \multicolumn{4}{|c|}{$\mathrm{pH}$} & \multicolumn{2}{|c|}{ 路着涟 (Millimol/g. Kohle) } \\
\hline & & 吸 & 等 前 & & 着 後 & (Glutaminsäure) & $\mathrm{Cl}-$ 或诘 $\mathrm{Na}^{+}$ \\
\hline 0.1 .5 & $\mathrm{HCl}$ & & 1.09 & & 1,12 & 0.252 & $0.423 \mathrm{Cl}-$ \\
\hline 0.1 & & & 1.34 & & 1.38 & 0.246 & 0.349 \\
\hline
\end{tabular}

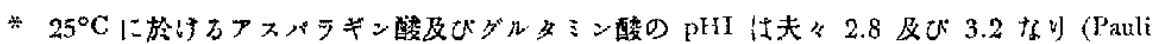

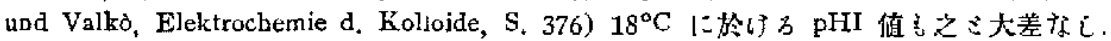

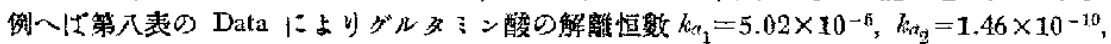

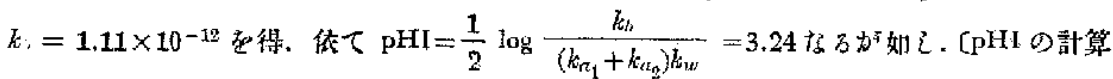
[2 Levene and Simms, Journ. Biol. Chem. 55, 801, (1923)，に據乃了. 


\begin{tabular}{l|r|r|r|r}
0.05 & 1.86 & 1.92 & 0.283 & 0.251 \\
0.025 & 2.35 & 2.41 & 0.349 & 0.136 \\
0.0125 & 2.72 & 2.78 & 0.362 & 0.081 \\
0.00625 & 2.99 & 3.04 & 0.377 & - \\
0.0031 & 3.16 & 3.18 & 0.375 & - \\
0 & 3.31 & 3.33 & 0.389 & - \\
$0.00078 \mathrm{NaOHI}$ & 3.35 & 3.35 & 0.397 & - \\
0.0031 & 3.45 & 3.61 & 0.397 & - \\
0.00625 & 3.63 & 3.73 & 0.380 & - \\
0.0125 & 3.90 & 4.07 & 0.338 & - \\
0.025 & 4.31 & 4.59 & 0.267 & -0.02 \\
0.03 & 4.45 & 4.70 & 0.205 & - \\
0.04 & 4.85 & 5.19 & 0.136 & -0.02 \\
0.045 & 5.20 & 5.54 & 0.086 & - \\
0.047 & 5.41 & 5.79 & 0.067 & 0.00 \\
0.05 & 7.43 & 7.24 & 0.041 & 0.00 \\
0.1 & 11.40 & 10.61 & 0.034 & 0.077 \\
0.15 & 12.81 & 12.77 & 0.027 & 0.127 \\
\hline
\end{tabular}

第九琶一Ty rosin.

\begin{tabular}{|c|c|c|c|c|c|c|}
\hline \multirow{2}{*}{\multicolumn{2}{|c|}{ 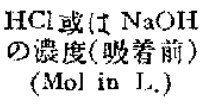 }} & \multicolumn{2}{|c|}{$\mathrm{pH}$} & \multicolumn{3}{|c|}{ 䂵着琶 (Millimolig, Kohle) } \\
\hline & & 吸着 剈 & 药着後 & Tyrosin & $\mathrm{Cl}^{-}$ & $\mathrm{Na}+$ \\
\hline $\begin{array}{l}0.2 \\
0.175 \\
0.15 \\
0.125 \\
0.075\end{array}$ & $\mathrm{NaOH}$ & $\begin{array}{r}0.91 \\
0.99 \\
1.12 \\
1.20 \\
10.37\end{array}$ & $\begin{array}{r}0.92 \\
1.01 \\
1.07 \\
1.16 \\
11.10\end{array}$ & $\begin{array}{l}0.629 \\
0.674 \\
0.698 \\
0.719 \\
0.445\end{array}$ & $\begin{array}{l}0.647 \\
0.611 \\
0.580 \\
0.559 \\
0.335\end{array}$ & $\mathrm{Na}^{+}$ \\
\hline $\begin{array}{l}0.1 \\
0.125 \\
0.15 \\
0.175 \\
0.2\end{array}$ & & $\begin{array}{l}11.50 \\
12.50 \\
12.77 \\
13.02\end{array}$ & $\begin{array}{l}11.91 \\
12.48 \\
12.75 \\
12.82 \\
13.00\end{array}$ & $\begin{array}{l}0.277 \\
0.170 \\
0.140 \\
0.128\end{array}$ & $\begin{array}{l}0.326 \\
0.279 \\
0.303 \\
0.259 \\
0.248\end{array}$ & - \\
\hline
\end{tabular}

チロシンは Amino-monocarbonsäure なれどるフェノール基を有す るが故に其吸着態度は案る Aminodicarbonsäure の夫に似たり。

无当，乙の溶解度の關係.上富驗籍 圍㤝局限せられたれぎも吸商曲線の 方向(第三圖)上り推世络之方亦 $\mathrm{pHI}$ に於て最多く吸着せらる〉ならむ。

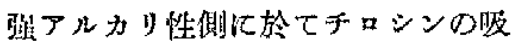
着量は $\mathrm{pH}$ D增火你して橆激に減 少するをみる・而して他の場合と相

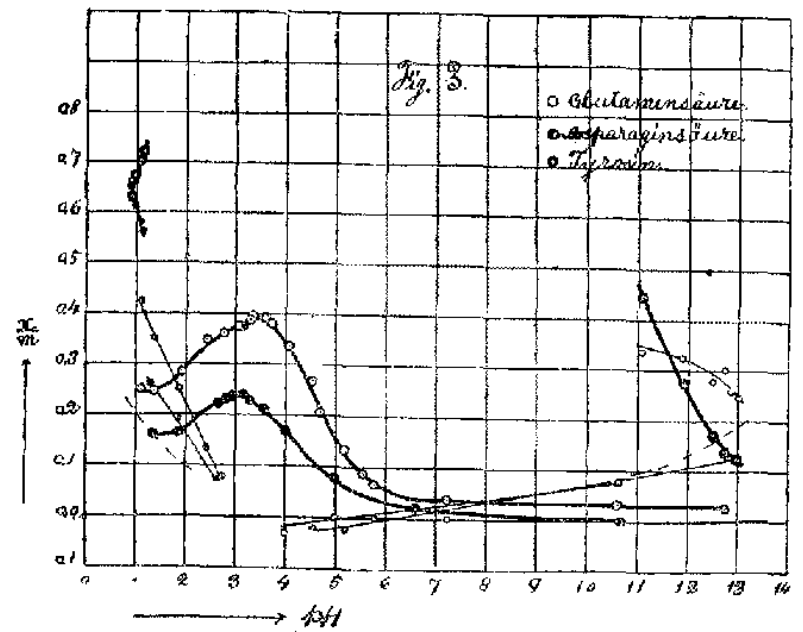




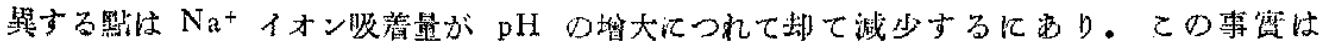

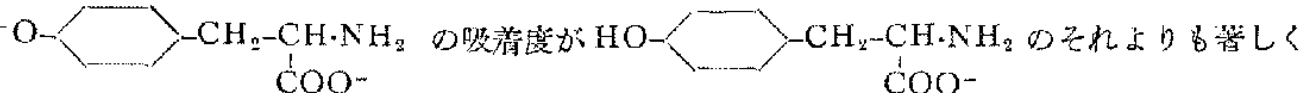
低き汇因ると解守る゙とと老得打。

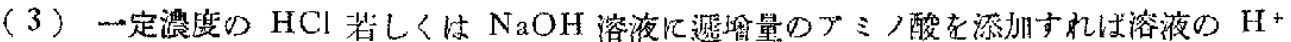

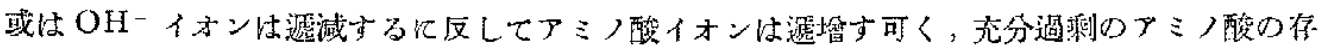

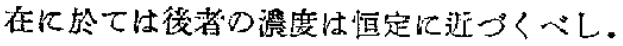

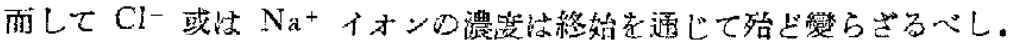

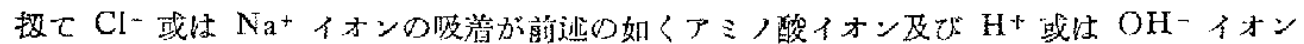

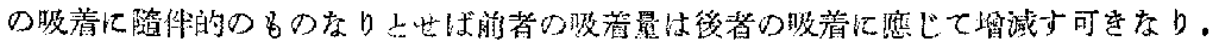

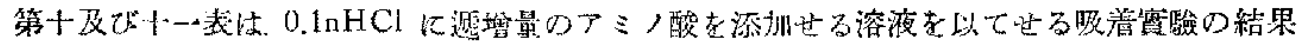

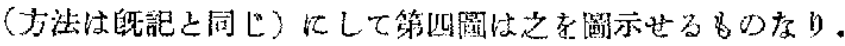

第一十鄢 $-0.1 \mathrm{nHCl}+\mathrm{C}-\mathrm{Mol}$ Aminosïure

\begin{tabular}{|c|c|c|c|c|c|c|}
\hline \multirow{3}{*}{ 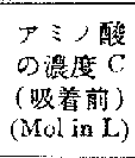 } & \multicolumn{3}{|c|}{ Alanin } & \multicolumn{3}{|c|}{ Norleucin } \\
\hline & \multirow{2}{*}{$\begin{array}{c}p^{\mathrm{I}} \\
\left(\boldsymbol{c}_{3} \mathrm{y}_{\mathrm{s}} \text { 後) }\right.\end{array}$} & \multicolumn{2}{|c|}{$\begin{array}{c}\text { 吸 着 } \\
\text { (Millinols. Kohle) }\end{array}$} & \multirow{2}{*}{$\begin{array}{c}\mathrm{pf} \\
\text { (吸着挍) }\end{array}$} & \multicolumn{2}{|c|}{ 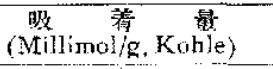 } \\
\hline & & $\mathrm{Cl}^{-}$ & Alanin & & $\mathrm{Cl}^{-}$ & Norleucin \\
\hline 0 & 1.14 & 0.184 & $\cdots$ & سبس & - & 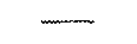 \\
\hline 0.0125 & - & - & $\ldots$ & $\longrightarrow$ & 0.338 & 0.217 \\
\hline 0.025 & - & - & - & 1.23 & 0.433 & 0.317 \\
\hline 0.05 & 1.43 & 0.224 & 0.031 & 1.39 & 0.492 & 0.454 \\
\hline 0.075 & 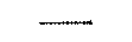 & $\longrightarrow$ & - & 1.53 & 0.503 & 0.537 \\
\hline 0.1 & 2.02 & 0.204 & 0.069 & 1.73 & 0.493 & 0.614 \\
\hline 0.13 & $\longrightarrow$ & - & $\longrightarrow-$ & 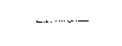 & 0.460 & 0.766 \\
\hline 0.15 & 2.26 & 0.222 & 0.144 & 2.15 & 0.432 & 0.782 \\
\hline 0.175 & 2.46 & 0.193 & 0.144 & & & \\
\hline 0.2 & - & 0.198 & 0.180 & & & \\
\hline
\end{tabular}

* Kirk and Schmide (Fauli und Valkó, loc. cit. 參照)に占んげ $25^{\circ} \mathrm{C}$ に玷けるチロシンの

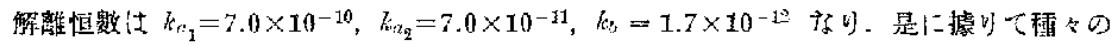

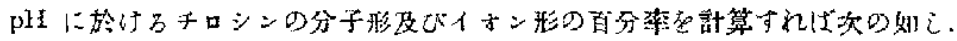

\begin{tabular}{|c|c|c|c|}
\hline p.EI & 山性分手形 & 一買 $\boldsymbol{~}$ & 二㵋アニオン秋 \\
\hline 11 & $0.8 \%$ & $58 \%$ & $40.8 \%$ \\
\hline 13 & $0.00 " \prime$ & $0.14^{\prime \prime}$ & $99.85 \prime \prime$ \\
\hline
\end{tabular}

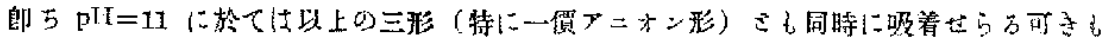

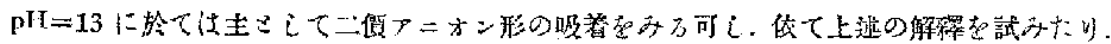




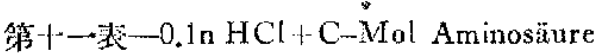

\begin{tabular}{|c|c|c|c|c|c|c|}
\hline \multirow{3}{*}{ 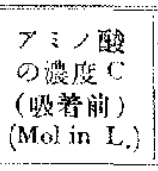 } & \multicolumn{3}{|c|}{ Glutamnsäure } & \multicolumn{3}{|c|}{ Tyrusin } \\
\hline & \multirow{2}{*}{$\begin{array}{c}\text { pII } \\
\text { (吸得㣪) }\end{array}$} & \multicolumn{2}{|c|}{$\begin{array}{l}\text { 影 } \\
\text { (Millimol/s, Konle) }\end{array}$} & \multirow{2}{*}{$\begin{array}{c}\mathrm{pH} \\
\text { (吸着绫) }\end{array}$} & \multicolumn{2}{|c|}{$\begin{array}{l}\text { 吸 落 } \\
\text { (Millimol/g, Kohle }\end{array}$} \\
\hline & & $\mathrm{Cl}^{-}$ & $\begin{array}{l}\text { Glutamin- } \\
\text { saure }\end{array}$ & & $\mathrm{Cl}^{-}$ & Tyrosin \\
\hline 0.005 & - & - & - & - & 0.270 & 0.091 \\
\hline 0.01 & - & - & - & 1.15 & 0.346 & 0.195 \\
\hline 0.015 & - & 0.258 & 0.133 & - & $0.4 n 8$ & 0.290 \\
\hline 0.02 & - & - & $\longrightarrow$ & 1.19 & 0.44 .3 & 0.394 \\
\hline 0.025 & - & 0.291 & 0.178 & 1.20 & 0.479 & 0.459 \\
\hline 0.03 & 一 & - & - & - & 0.511 & 0.518 \\
\hline 0.04 & - & - & - & 1.27 & 0.545 & 0.623 \\
\hline 0.05 & 1.38 & 0.334 & 0.246 & & & \\
\hline 0.07 & 1.51 & 0.331 & 0.282 & & & \\
\hline 0.08 & - & 0.340 & 0.292 & & & \\
\hline 0.09 & - & 0.351 & 0.349 & & & \\
\hline 0.1 & 1.76 & 0.342 & 0.425 & & & \\
\hline 0.12 & 1.87 & 0.344 & 0.473 & & & \\
\hline 0.14 & - & 0.339 & 0.535 & & & \\
\hline 0.15 & 2.02 & 0.314 & 0.569 & & & \\
\hline
\end{tabular}

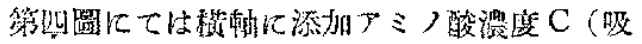

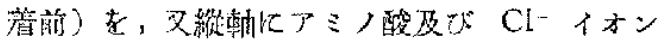

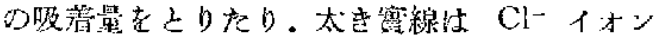
の吸喓曲線儿して他はアミノ酸の夫なり：一

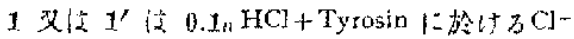

メ估チロシンの昅着曲線

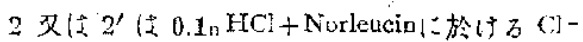

又注ノルロイシンの昅着曲線

3 㕛位 $3^{\prime}$ 位 $0.1_{n} \mathrm{HCl}+$ Glutaminsäure

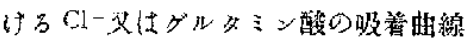

4 又仕 $4^{\prime} 0.1 \mathrm{nHCl}+$ Alanin 1 於讨

アランンの明着帕線

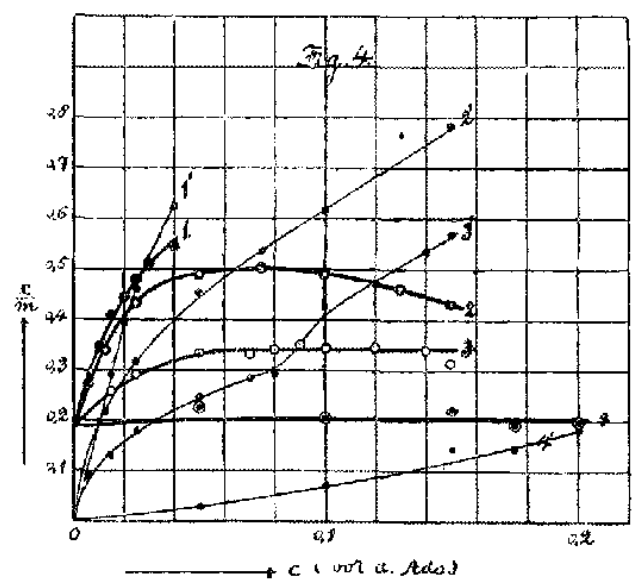

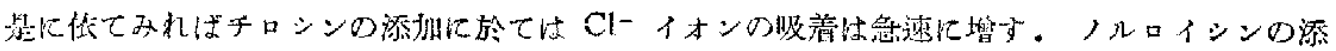

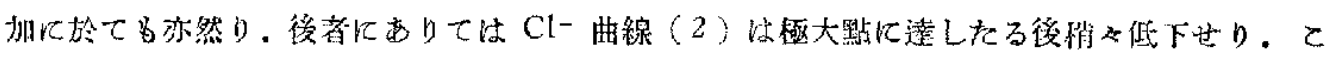
の事蜜は次の如く說明するを得さ。

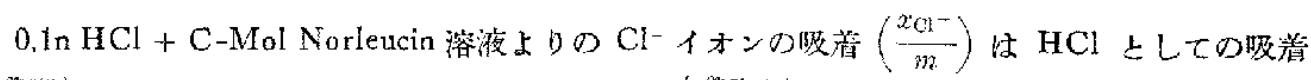

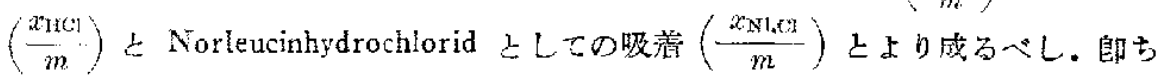

$$
\frac{x_{\mathrm{Cl}^{-}}}{m}=\frac{x_{\mathrm{HCl}}}{m}+\frac{n_{\mathrm{MI}} \mathrm{Ol}}{m}
$$




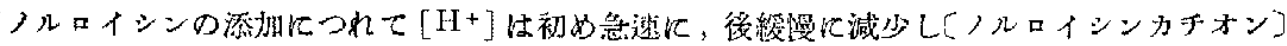

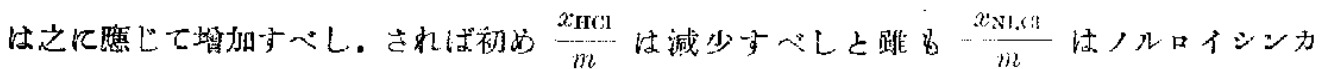

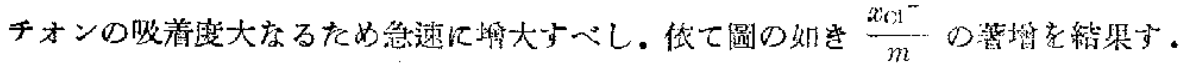

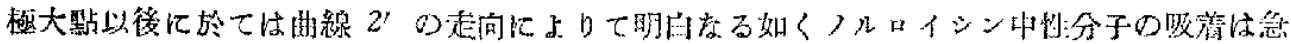

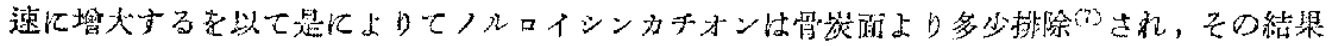

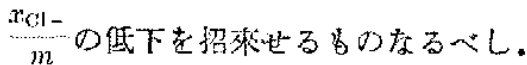

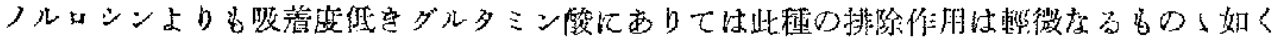

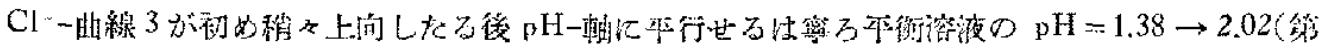

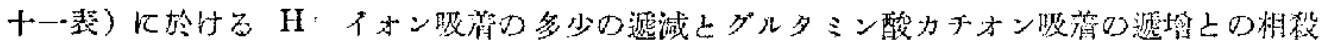
に閭すぺし。

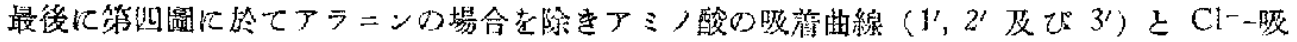

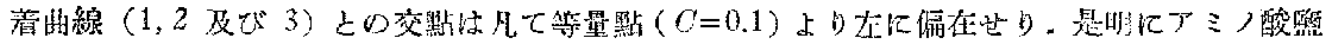

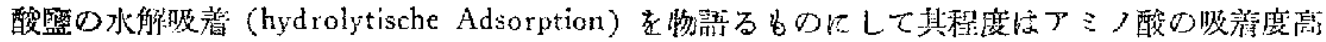

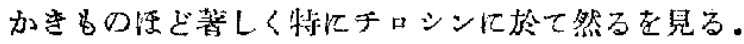

第十二裴一 $0.05 n \mathrm{naOH}+\dot{\mathrm{C}}-\mathrm{Mol}$ Aminosiure.

\begin{tabular}{|c|c|c|c|c|c|c|}
\hline \multirow{3}{*}{ 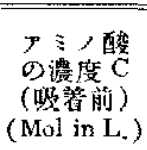 } & \multicolumn{3}{|c|}{ Norleucin } & \multicolumn{3}{|c|}{ Alanin } \\
\hline & \multirow{3}{*}{$\begin{array}{c}\text { plI } \\
\text { (吸着後) } \\
12.69\end{array}$} & \multicolumn{2}{|c|}{ (M/limollg. Kohle) } & \multirow{2}{*}{$\begin{array}{c}\mathrm{pH} \\
\text { (洊着後) }\end{array}$} & \multicolumn{2}{|c|}{ (Mfillimolg. Kohle) } \\
\hline & & $\mathrm{Na}+$ & Norleucin & & $\mathrm{Na}^{+}$ & Alarin \\
\hline$\theta$ & & 0.178 & - & - & - & $\ldots . .$. \\
\hline 0.0062 & - & 0.189 & 0.078 & - & 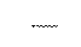 & - \\
\hline 0.0125 & $m$ & 0.242 & 0.138 & - & 0.138 & 0.00 \\
\hline 0.025 & - & 0.290 & 0.185 & - & 0.135 & 0.01 \\
\hline 0.014 & - & 0.293 & 0.230 & - & -- & - \\
\hline 0.05 & 11.23 & 0.260 & 0.333 & 10.79 & 0.070 & 0.034 \\
\hline 0.06 & $\ldots$ & 0.241 & 0.425 & - & - & - \\
\hline 0.075 & 10.48 & 0.192 & 0.514 & 10.07 & 0.037 & 0.052 \\
\hline 0.1 & 10.13 & 0.156 & - & & & \\
\hline
\end{tabular}

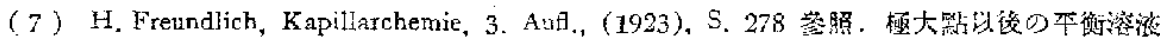

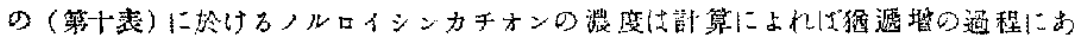

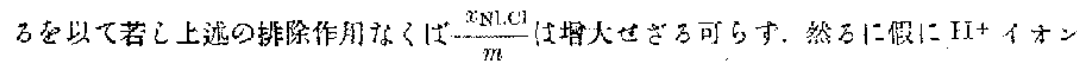

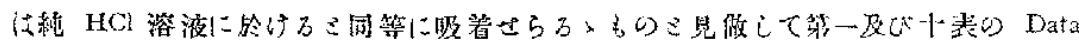

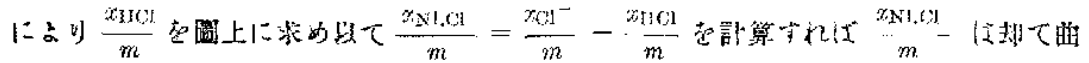

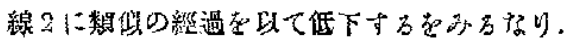


第中一表-0.05n NaOH + C-Mol Aminosäure.

\begin{tabular}{|c|c|c|c|c|c|c|}
\hline \multirow{3}{*}{ 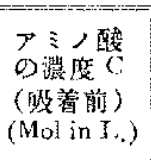 } & \multicolumn{3}{|c|}{ Glutaminsäure } & \multicolumn{3}{|c|}{ Tyrosin } \\
\hline & \multirow{2}{*}{$\begin{array}{c}\text { pH } \\
\text { (㺼精德) }\end{array}$} & \multicolumn{2}{|c|}{ 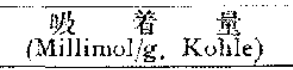 } & \multirow{2}{*}{$\begin{array}{c}p^{E l} \\
\text { (吸箐後) }\end{array}$} & \multicolumn{2}{|c|}{ 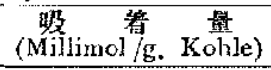 } \\
\hline & & $\mathrm{Na}^{+}$ & $\begin{array}{l}\text { Glutamin- } \\
\text { săure }\end{array}$ & & $\mathrm{Na}^{+}$ & Tyrosin \\
\hline 0.00625 & - & - & - & 12.56 & 0.162 & - \\
\hline 0.01 & - & - & - & - & 0.186 & - \\
\hline 0.0125 & - & 0,111 & - & 12.41 & 0.140 & 0.071 \\
\hline 0.025 & - & 0.049 & 0.00 & 11.73 & 0.262 & 0.190 \\
\hline 0.04 & - & 0.025 & 0.014 & 10.92 & 0.286 & 0.410 \\
\hline 0.05 & 7.24 & 0.00 & 0.041 & & & \\
\hline 0.06 & - & 0.00 & 0,101 & & & \\
\hline 0.075 & 4.79 & -0.028 & 0.223 & & & \\
\hline 0.1 & 4.43 & -0.031 & - & & & \\
\hline
\end{tabular}

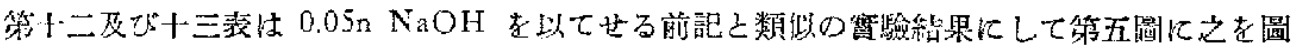
示せり :-

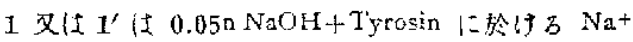
刃隹チロシンの昨着陆線

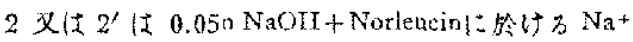
叉仕ルロイシンの吸着曲線

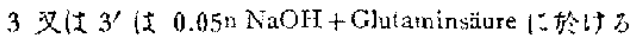

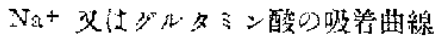

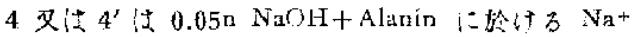
义はアラーンの吸曾曲線

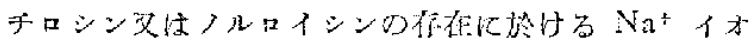

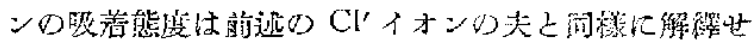

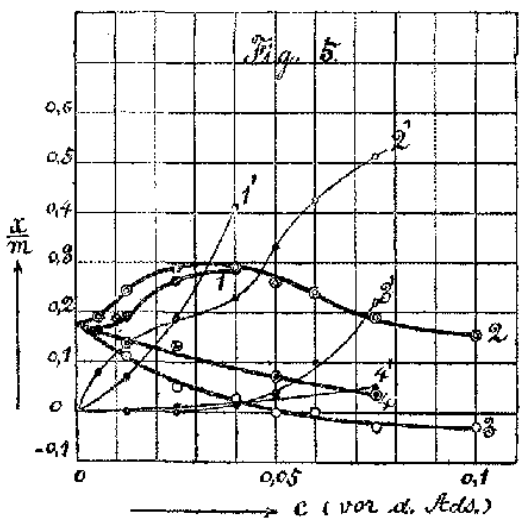

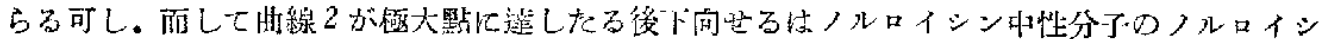

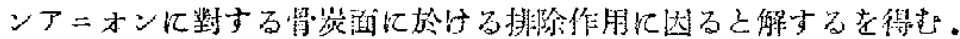

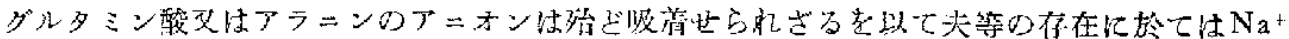

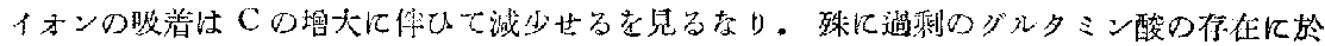

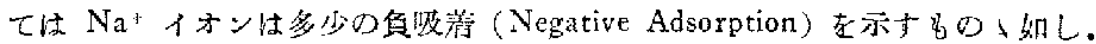

\section{總括}

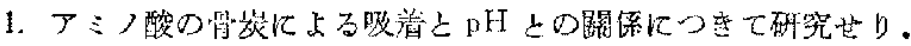

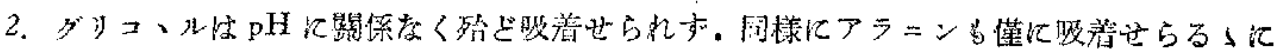
過窎市。

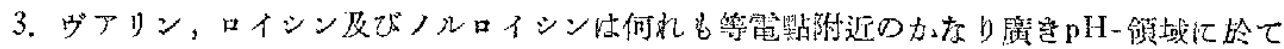

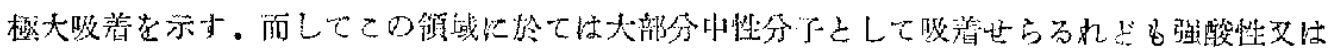

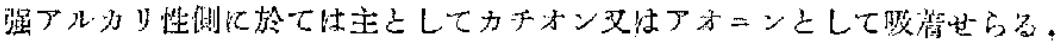




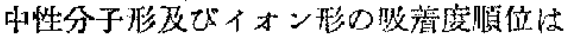

$\mathrm{H}_{2} \mathrm{~N} \cdot \mathrm{R} \cdot \mathrm{COOH}$ (或U住恐ら< $\mathrm{H}_{3}{ }^{+} \mathrm{N} \cdot \mathrm{R} \cdot \mathrm{COO}-\mathrm{POH}_{2}{ }^{+} \mathrm{N} \cdot \mathrm{R} \cdot \mathrm{COOH}>\mathrm{H}_{2} \mathrm{~N} \cdot \mathrm{R} \cdot \mathrm{COO} \mathrm{O}^{-}$

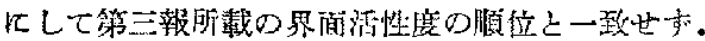

4. 同一の $\mathrm{pH}$ に於けるアミノ酸各㮯の吸着度圭比较すれは土常に

Norleucin > Leucin> Valin> Alanin> Glykokoll

の順位にして此點は界面活性度り順位と一致す。

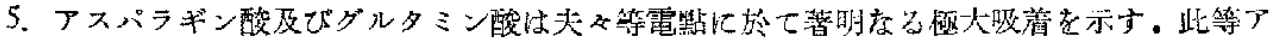
ミノ酸のカチオンはかなり吸着せらるれどもアニオン恬ど吸雇せられで。 チロシンの吸着宗此等りそれ行類似世り。

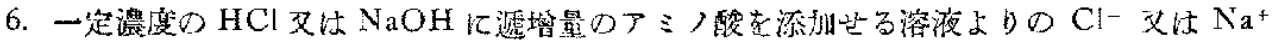

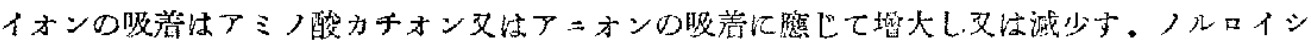

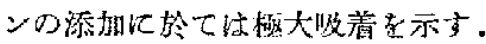

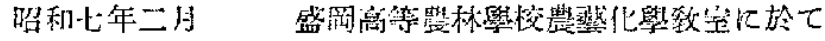

文敛

(1) Compt, rend., 179, 972, (1924).

(2) Proc. Roy. Soc. London, A, 124, 554, (1929).

(3) Juirn. Phys. Chem, 30, 1031, (1926).

(4) L. Michaelis, Die Wasserstoflionenkonzentration I.;

P. Rona u. I., Michaelis, Bixchem. Z., 94, 250, (1919) 客照.

(5) T. Michaeis, lus, cit.

(6) J. Phys, Chem., 32, 829, (1928). 